\title{
Resistance to reinfection in rats induced by irradiated metacercariae of Clonorchis sinensis
}

\author{
Fu Shi Q uan, Jeong Beom Lee/*/**/+ Jun Sang Bae**, Nobu 0 hwatari*, Young Ki Min**, \\ Hun Mo Yang**
}

\author{
Microbiology and Immunology, School of Medicine, Emory University, Atlanta, GA 30322 US *Department of Environmental \\ Physiology, Institute of Tropical Medicine, Nagasaki University, Nagasaki, Japan **Department of Physiology, \\ College of Medicine, Soonchunhyang University, Cheonan, Choongnam, 330-090, Republic of Korea
}

A study was made to observe the association between the resistance to reinfection induced by irradiated metacercariae (MC) of Clonorchis sinensis and antigen specific Th1- and Th2-type cytokine productions in rats. Rats were infected with $20 \mathrm{MC}$ of $\mathrm{C}$. sinensis, previously exposed to a single dose of gamma irradiation, which varied from 0 to $100 \mathrm{~Gy}$. All of them, single dose of 12 Gy showed higher IgG antibody titer with lowest worm recovery. Thus, $50 \mathrm{MC}$ were used to challenge infection in rats previously infected with $20 \mathrm{MC}$ irradiated at $12 \mathrm{~Gy}$ and the highest resistance to challenge infection was observed. The results of lymphocyte proliferation with specific antigen, ES Ag were shown no difference of proliferative responses as compared with primary and challenge infection at 12 Gy irradiation dose. In the case of cytokines production were observed that interferon (IFN- $\gamma)$ and interlukin (IL-2) were significantly enhanced, while IL-4 and IL-10 was almost unchanged to make comparison between primary and secondary infection at 12 Gy irradiation dose. In conclusion, the single dose of 12 Gy could be adopted for induction of the highest resistance to challenge infection. Up-regulation of Th1 type cytokines, IFN- $\gamma$ and IL-2 may be affected to develop vaccine by irradiated $M C$.

Key words: irradiation - metacercariae - reinfection - interferon- $\gamma$ - interlukin-2

Liver fluke infection caused by Clonorchis sinensis is still an important public health problem in many countries of the West Pacific area. It is estimated that about 30 million people are infected annually with $C$. sinensis or Opisthorchis viverrini by eating uncooked fresh water fish in Southeastern Asia (Rim et al. 1981, Akai et al. 1994). Studies about effects of irradiation on infective stage of C. sinensis have been reported (Lee et al. 1989, Song et al. 1992, Duan et al. 1993), and reports show that suitable dose of irradiation on isolated metacercariae (MC) or unisolated MC in fish can prevent infections. There are evidences from immunological studies that man and animals produce antibodies and cellular immunity after $C$. sinensis infections (Choi \& Park 1987, Choi et al. 1990, Hagan et al. 1991, Akai et al. 1994, Quan et al. 2000, 2002). To the best of our knowledge no study was carried out on the association between the effects of gamma irradiation and immune responses in clonorchiasis. However, study on Schistosoma mansoni showed that high levels of protection have been achieved in mice against $S$. mansoni infection using gamma irradiated cercarial vaccines (Dean 1983, Coulson 1997). Also Th1- or Th2-type cytokines were reported to associate with protective immunity against various parasites (Stevenson \& Tam 1993, Cetre et al. 1999,

Financial partial support: grant-in-Aid 20040158 for Scientific Research for Soonchunhyang Medical Research Institute, Soonchunhyang University, Korea

+Corresponding author. E-mail: leejb@sch.ac.kr

Received 18 January 2005

Aceepted 19 May 2005
Koyama et al. 1999). In the present study, $C$. sinensis MC were first treated with different dose of gamma irradiation to select the suitable dose for the study of immune responses. Then resistance to reinfection induced by irradiated MC of $C$. sinensis was evaluated and an association between resistance and Th1- and Th2-type cytokines were observed.

\section{MATERIALS AND METHODS}

Parasites and experimental animals - SpragueDawley (SD) rats (female, 8 wk old) were purchased (Samyook animal center, Osan-shi, Kyonggi-do, South Korea) and used for whole experimental process. Parasites $C$. sinensis MC collected from Pseudorasbova parva were used for infection of rats and rabbits. Male white rabbits (New Zealand white) about 1.5 to $2 \mathrm{~kg}$ were used to recover adult $C$. sinensis for collection of $C$. sinensis excretory-secretory antigen (ES Ag). All procedures involving animals and their care were in conformity with institutional guidelines that comply with national and international laws and policies.

Irradiation - MC were dispensed into each micro tube (1.5 ml) containing $200 \mu \mathrm{l}$ saline. The MC in the tube were given irradiation with single dose from 0 to $100 \mathrm{~Gy}$ ( $1 \mathrm{~Gy}=$ $100 \mathrm{rad}$ ) and irradiated at the rate $375 \mathrm{rad} / \mathrm{min}$ at $70 \mathrm{~cm}$ distance from the source, using 60 Co (Thrateron 780, AECL, Canada) gamma-ray.

Antigen preparation - C. sinensis $\mathrm{MC}$ were collected from $P$. parva and digested with artificial gastric juice, and orally administered to the experimental rabbits. Then adult worms were collected from rabbit liver after three month of infection. C. sinensis excretory-secretory antigen (ES $\mathrm{Ag}$ ) was obtained by culturing living adult worm in RPMI 
1640 medium supplemented with antibiotics at $37^{\circ} \mathrm{C}$ and $5 \% \mathrm{CO}_{2}$. Culture medium was collected every two days and new medium was added to culturing living adult worm. Collected medium was centrifuged at $4^{\circ} \mathrm{C}, 10,000 \mathrm{rpm}$ for $30 \mathrm{~min}$, and the supernatant was used as ES Ag and stored at $-70^{\circ} \mathrm{C}$ for use. Protein concentration of antigens was analyzed by the DC Protein Assay kit (Bio-Rad Lab, Hercules, CA, US) and stored at $-70^{\circ} \mathrm{C}$ until used.

Study design - To determine the relationship between survival of worms and irradiation dose, rats were given irradiated MC of single dose that varied from 0 to $100 \mathrm{~Gy}$. Then worm recovery and IgG antibody responses were measured. Thus, irradiation dose was selected with the highest titer of $\operatorname{IgG}$ and the lowest worm recovery. For the study of resistance to reinfection induced by selected irradiation dose and cytokine production, the experiment groups were designed as follows: uninfected control, rats infected with normal MC (non-irradiated MC), rats infected with irradiated $\mathrm{MC}$, rats received challenge infection, previously infected with normal MC. Each group contained 10 rats.

Primary infection and challenge infection - In the experiments, rats were infected with 20 normal or 20 irradiated $\mathrm{MC}$ in the primary infection. After one month, challenge infections were given with 50 normal MC via orogastric tube under light ether anesthesia (Quan et al. 2000, 2002).

Worm recovery and evaluation of protection - Worms were collected in the liver duct of rats in 4th week in the primary infection for the determination of irradiation dose. Worm recovery for evaluation of resistance was performed in 4th week after challenge infection. Protection was evaluated by comparing the adult worms recovered from experimental groups and control group.

Sera collection - Blood was collected from each rat in week 4 after primary infection during the selection of irradiation dose. Blood was allowed to clot at room temperature and stored at $4^{\circ} \mathrm{C}$. After removal of the clot, the sera were centrifuged at $3000 \mathrm{rpm}$ for $10 \mathrm{~min}$ and stored at $-20^{\circ} \mathrm{C}$ until needed. Sera were used to measure IgG levels.

Enzyme-linked immunosorbent assay (ELISA) - The solid phase ELISA test was performed in a microtiter plate as described elsewhere (McLaren et al. 1978) with some modifications. Plates for $\mathrm{IgG}$ was coated with $5 \mu \mathrm{g} / \mathrm{ml} C$. sinensis ES Ag. Serum samples were diluted 1:100. Peroxidase-conjugated goat affinity purified antibody rat $\operatorname{IgG}$ (Cappel, Durham, NC, US) in 1:1000 dilutions were used in duplicate wells. The reactions were stopped using $5 \mathrm{~N}$ $\mathrm{H}_{2} \mathrm{SO}_{4}$ and the $\mathrm{OD}$ at $490 \mathrm{~nm}$ was recorded using an ELISA reader (Molecular Devices, Menlo Park, CA, US).

Lymphocyte proliferation assay - For detection of lymphocyte proliferation and cytokine production, lymphocytes in mesenteric lymph nodes (MLN) were collected in the 4th week after primary or secondary infection. MLN were excised from rats and cell suspensions were aseptically prepared by squeezing the MLN between two sterile glass slides. Lymphocytes were pooled from 5 rats and cultured at a final concentration of $5 \times 10^{6}$ cells in $200 \mu \mathrm{l}$
RPMI 1640 supplemented with $10 \%$ fetal bovine serum, 100 units of penicillin/streptomycin, $2 \mathrm{mM}$ glutamine, 25 mM HEPES, $1 \%$ non-essential amino acid solution, $0.1 \%$ $5 \times 10^{-2} \mathrm{M} 2$-mercaptoethanol and $1 \%$ sodium pyruvate (Invitrogen Co., Grand Island, NY, US). Cultures were performed in 96-well flat bottom culture plates for three days at $37^{\circ} \mathrm{C}$ in $93 \%$ air and $5 \% \mathrm{CO}_{2}$. Cells were stimulated with ES Ag at $25 \mu \mathrm{g} / \mathrm{ml}$, or phytohemaglutinin (PHA) at $10 \mu \mathrm{g} /$ $\mathrm{ml}$ final concentration. Each test was performed three times. Cells were pulsed for the last $18 \mathrm{~h}$ with $0.5 \mu \mathrm{Ci} /$ well $\left[{ }^{3} \mathrm{H}\right]$ thymidine (Amersham Co., Arlington Heights, IL, US) and then harvested on glass fibre filters with a semi-automatic cell harvester (Skatron, Norway). Incorporated radioactivity was measured in a liquid scintillation counter (LKB 1214 Racbeta) and expressed as geometric means after subtracting the background counts $(\triangle \mathrm{CPM})$.

Cytokine analysis - For detection of cytokine production, triplicate cultures of $5 \times 10^{6}$ cells as described above were incubated with antigens in 96-well culture plates at $37^{\circ} \mathrm{C}$ for three days, in $5 \% \mathrm{CO}_{2}$. The supernatants of three wells were pooled following centrifugation and stored at $-70^{\circ} \mathrm{C}$. The concentrations of interferon (IFN- $\gamma$ ) and interleukins (IL-2, IL-4, IL-10) were determined in the culture supernatants by rat Cytoscreen ${ }^{\mathrm{TM}}$ Immunoassay Kits (Biosource, California, US).

Statistical analysis - Statistical significant differences from all groups were carried out using ANOVA of SAS system. A value of $P<0.05$ was considered significant. Cytokine productions were carried out using pooled cells from five rats and as such were not subject to statistical analysis.

\section{RESULTS}

Relationship between survival of worms and irradiation dose - Some different number of adult worms was recovered from rats infected with 20 irradiated or nonirradiated MC of $C$. sinensis after four weeks of infection. As shown in Fig. 1, worm burdens were reduced following increasing dose of radiation. Worms were recovered when MC were irradiated at 1, 3, 5, 7, 10, and 12 Gy irradiation dose, including non-irradiated control (0 Gy) (Fig. 1), whereas we could not observe survival worms at 15,20, 40, 60, and 100 Gy irradiation dose.

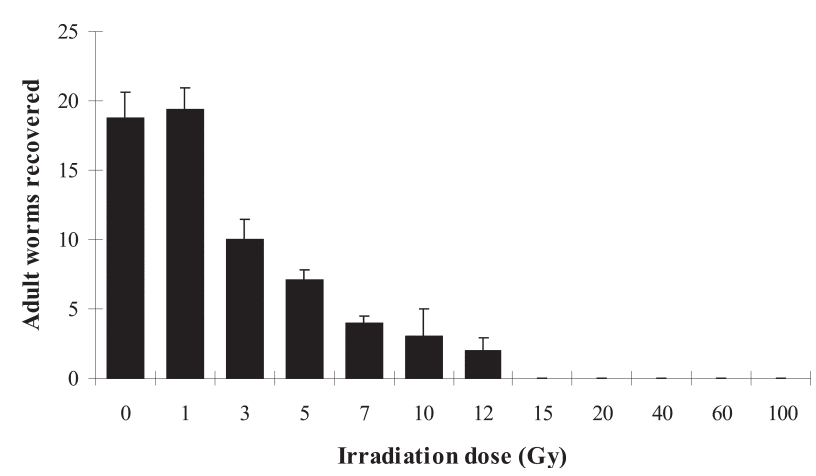

Fig. 1: adult worms were recovered in rats on week 4 after infection with the Clonorchis sinensis metacercariae irradiated with different dose. 
Antibody responses in rats infected with irradiated $M C$ - All rats ( $\mathrm{n}=9 /$ each dose) had been infected with MC irradiated with a range of dose (1-20 Gy) showed significant increases in $\operatorname{IgG}$ antibody responses from 1 to $12 \mathrm{~Gy}$ range compared with the uninfected control (Fig. 2, $P<$ $0.01)$. But, IgG antibody responses are low level in rats infected with 15 and 20 Gy irradiated MC. These data are consistent with the above that adult worms were recovered from the range of 1 to $12 \mathrm{~Gy}$. The high antibody responses were detected in rats infected with 1 and $12 \mathrm{~Gy}$ irradiated MC, including non-irradiated ( 0 Gy) MC.

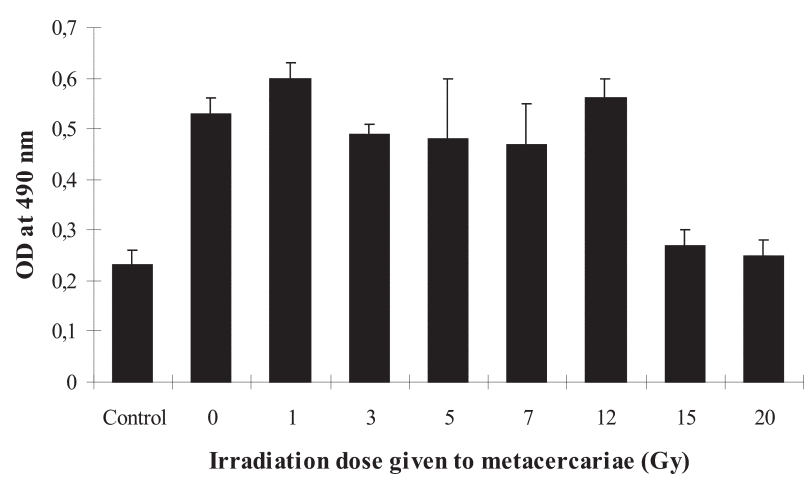

Fig. 2: IgG antibody responses from sera samples of rats infected with irradiated metacercariae (MC) of Clonorchis sinensis $(\mathrm{n}=9 /$ each dose). Each rat was given $20 \mathrm{MC}$ irradiated with different dose.

Resistance to reinfection - For detection of resistance to reinfection, rats were primarily infected with 20 irradiated MC ranging from 7 to $15 \mathrm{~Gy}$. Then challenge infections were performed in rats using 50 non-irradiated MC after four weeks of primary infection. Fig. 3 showed that the number of $C$. sinensis adult worms recovered from rats was gradually decreased from range of 7 to $12 \mathrm{~Gy}$, in which the highest resistance to reinfection was found in 12 Gy irradiation dose. Whereas high worm burdens were recovered in rats when challenge infection was carried out after primary infection with 15 Gy irradiated MC (Fig. $3)$. This result is the same as when rats only received challenge infection. And because these data are consistent with high $\operatorname{IgG}$ antibody responses in rats infected with $12 \mathrm{~Gy}$ irradiated MC, we assumed that MC died, and therefore lost ability to infect rats when MC were irradiated with dose over $15 \mathrm{~Gy}$.

Lymph node cell proliferation and cytokine production - C. sinensis adult ES Ag specific stimulated proliferative responses of MLN cells were determined in relation to resistance. Twelve Gy irradiation dose was chosen to evaluate proliferative activity in primary and secondary infection. ES Ag specific stimulated proliferative responses were similar level with primary and secondary infection at $12 \mathrm{~Gy}$ irradiation dose (Fig. 4). Cytokine productions by $C$. sinensis ES Ag specific stimulated MLN cells were also measured in selected 12 Gy irradiation group. IFN- $\gamma$ and IL- 2 were mainly increased in secondary infections to compare with primary infection, whereas IL-4 and IL-10 were almost same level with primary and secondary infections at 12 Gy irradiation dose (Fig. 5).

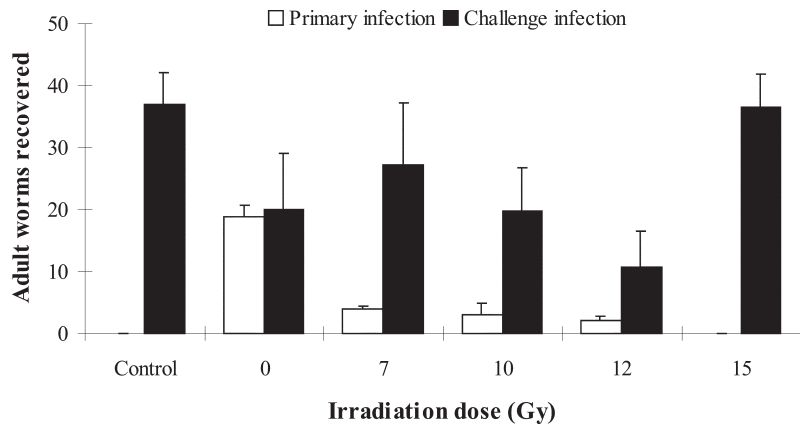

Fig. 3: worms were recovered from rats infected with primary infection or secondary infection. Primary infections were performed 20 irradiated metacercariae (MC), secondary infections were given 50 non-irradiated MC. Irradiation varied on dose $0,7,10,12$, and 15 Gy. Fifty MC were just infected to rats without primary infection in control group.

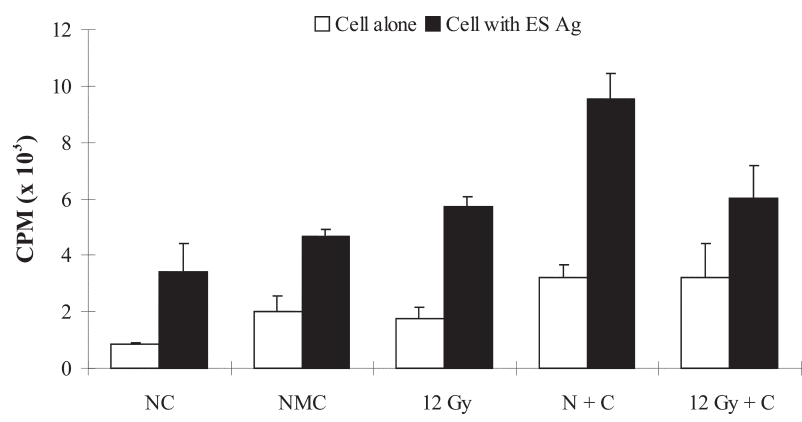

Fig. 4: in vitro proliferation of lymphocytes from rat mesenteric lymph nodes (MLN). Cellular proliferation was evaluated by $\left[{ }^{3} \mathrm{H}\right]$ thymidine incorporation on three days cultures with medium (cell alone) and in the presence of $10 \mu \mathrm{g} / \mathrm{ml}$ Clonorchis sinensis ES Ag. NC: normal control; NMC: non-irradiated metacercariae (MC) control; 12 Gy: MC irradiated with $12 \mathrm{~Gy} ; \mathrm{N}+\mathrm{C}$ : challenge infection after primary infection with non-irradiated $\mathrm{MC} ; 12 \mathrm{~Gy}+\mathrm{C}$ : challenge infection after primary infection with 12 Gy-irradiated MC.

\section{DISCUSSION}

Attempts to induce protection induced by $\gamma$-irradiated infective stages were performed in some parasites, Fasciola hepatica, S. mansoni, S. japonicum, Loa loa, Brugia malayi, Achantocheilonema viteae, B. pahangi (Creaney et al. 1995, Zhang et al. 1999, Ungeheuer et al. 2000). In these studies, that the infective larvae when optimally attenuated cannot develop into adults will die in the host, which induce high level of protection was proved. Differences in irradiation dose, number of vaccination and host showed different effects (Zhang et al. 1999).

This study is about the resistance induced by irradiated MC of $C$. sinensis. Previous studies on parasite $C$. sinensis showed that $50 \mathrm{~Gy}$ irradiation doses on isolated MC or $150 \mathrm{~Gy}$ on fish is an effective control measure that can be used in preventing MC (Lee et al. 1989, Song et al. 1992). Present study used different doses that varied from 1 to 100 Gy to select optimal dose, in which worms remained the least in rats to reduce damage of liver tissue (Fig. 1). Thus, $12 \mathrm{~Gy}$ irradiated MC was selected in which 

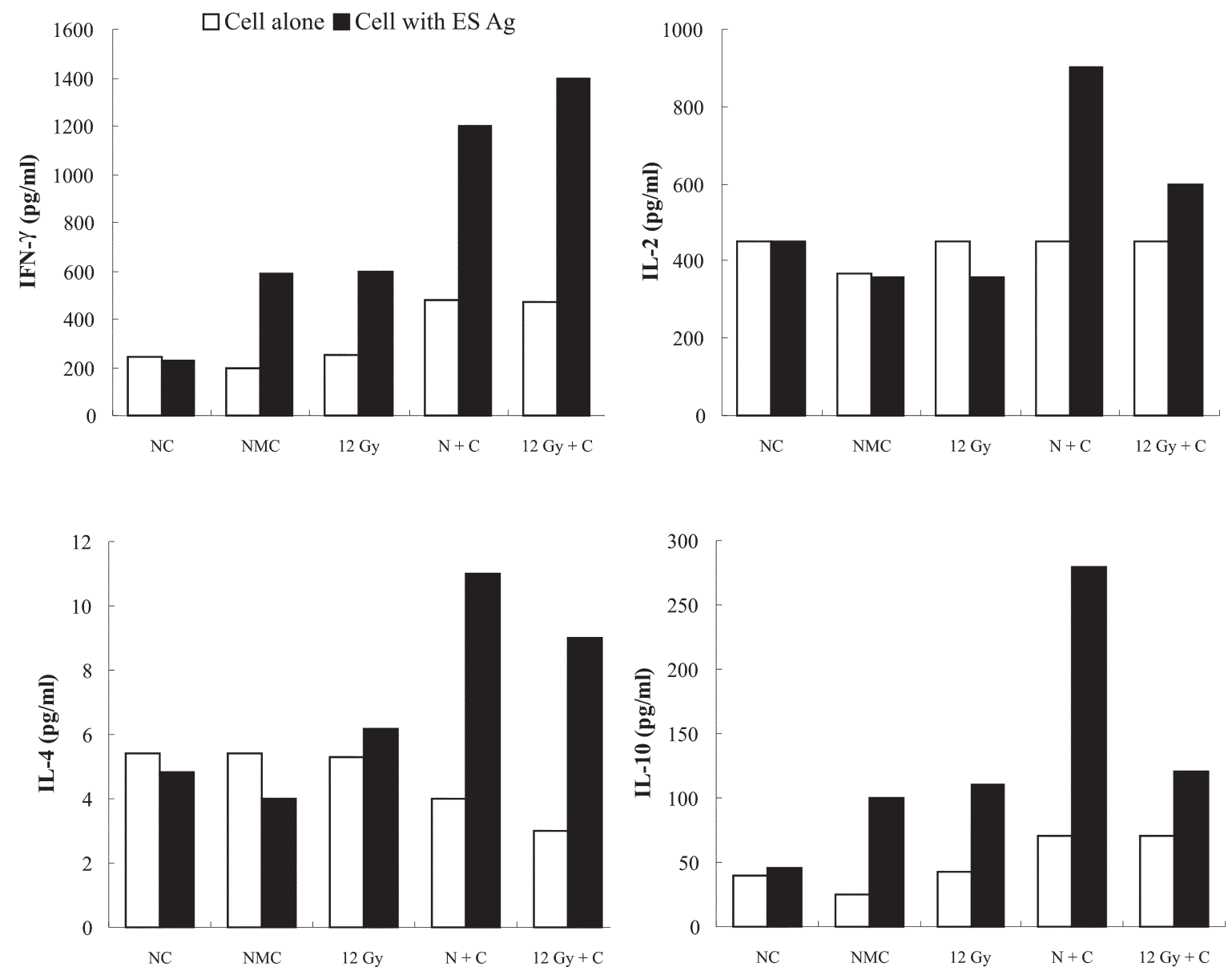

Fig. 5: in vitro production of cytokines, interferon (IFN- $\gamma$ ) and interlukins (IL-2, IL-4, IL-10), from rat mesenteric lymph nodes (MLN). NC: uninfected control; NMC: non-irradiated metacercariae control; 12 Gy: metacercariae irradiated with 12 Gy; N + C: challenge infection after primary infection with non-irradiated metacercariae; $12 \mathrm{~Gy}+\mathrm{C}$ : challenge infection after primary infection with $12 \mathrm{~Gy}-$ irradiated metacercariae. In this experiment, it used lymphocytes that were pooled from five rats.

rats showed high level of $\mathrm{IgG}$ antibody responses to the same level as those infected with non-irradiated MC (Fig. 2). Rats showed no antibody responses and no worms were recovered from 15 to 100 Gy irradiation dose compared to uninfected control and non-irradiated rat control. It may be that no worms survived on these irradiation doses. So an attempt to induce resistance was carried out on $12 \mathrm{~Gy}$ irradiation doses, in which worm burdens were significantly decreased after challenge infection (Fig. 3).

Little is known about the mechanisms by which protection against parasite infection is induced by irradiation-attenuated vaccines, but several studies have been performed including disruption of protein synthesis, changes in carbohydrate expression (Wales \& Kusel 1992), alteration of parasite antigens, alteration of expression of cathepsin-B protease and WGA- and Con A-specific sugars which may be detrimental to parasite invasion and contribute to the protective immune responses generated in the host (Creaney et al. 1996). Maybe $12 \mathrm{~Gy}$ irradiation dose can induce maximum changes described above correlated with the capacity of the irradiated larvae (highest level of antibody responses) to protect rat against subsequent challenge with non-irradiated MC. Different levels of antibody responses from different doses need further study.

Our findings in this study indicated that ES Ag specific stimulated proliferative responses and cytokines productions were elicited. When the cytokines production compared to infection with $12 \mathrm{~Gy}$ irradiated MC and challenge infection with non-irradiated $\mathrm{MC}$ at $\mathrm{ES} \mathrm{Ag}$ group, IFN- $\gamma$ and IL- 2 were significantly enhanced. This result indicates that irradiated MC like attenuated vaccine is able to induce Th1-type cytokines (IFN- $\gamma$ and IL-2) and these cytokine effect to protection against $C$. sinenis infection. Resistance to different parasitic diseases has been associated with the both of Th1- or Th2-type immune responses. Different T-helper subsets appear when different parasite is presented in a host, or if the duration of infection is altered. S. mansoni infection can drive Th2 responses in rats or in mice and it favors protective immunity against reinfection (Cetre et al. 1999). Trichinella spiralis infection shows mixed Th1/Th2 response in rats (Stewart et al. 1999), Trichuris muris shows Th2-type response in mice involved in protective immunity (Koyama 
et al. 1999). Chronic infection with Taenia crassiceps is characterized by high levels of production of both Th1 and Th2 cytokines in mice (Spolski et al. 2000). Mice showed low parasite numbers when receiving recombinant cytokines IFN- $\gamma$ and IL-2, whereas significant increases in parasite loads were found when mice receiving IL-10 (Terrazas et al. 1999). It is well known that Th1-type response helps to eliminate intracellular microorganisms, whereas a Th2-type response specializes in the control of extra-cellular pathogens (Cox \& Liew 1992, Stevenson \& Tam 1993, Reiner \& Locksley 1993). Development of an inappropriate immune response can be ineffective and even pathogenic to the host (Romagnani 1997). In Leishmania major infection, IL-10 administration leads to a higher parasite persistence in a mouse model and influenced the outcome of the disease by modifying the inflammation and local cell recruitment at the site of parasite penetration (Viana da Costa et al. 2002).

In conclusion, the single dose of 12 Gy could be adopted for induction of the highest resistance to challenge infection of $C$. sinensis. After primary infection with 12 Gy irradiated $C$. sinensis, reinfection with non-irradiated $C$. sinensis is induced high levels of production of IFN- $\gamma$ and IL-2. These Th1-cytokines were involved in protecting against $C$. sinenis reinfection.

\section{REFERENCES}

Akai PS, Pungpak S, Kitikoon V, Bunnag D, Befus AD 1994. Possible protective immunity in human opisthorchiasis. Parasite Immunol 16: 279-288.

Cetre C, Pierrot C, Cocude C, Lafitte S, Capron A, Capron M, Khalife J 1999. Profiles of Th1 and Th2 cytokines after primary and secondary infection by Schistosoma mansoni in the semipermissive rat host. Infect Immun 67: 2713-2719.

Choi DW, Park MK 1987. Transfer of immunity by metablic products and somatic constituents of Clonorchis sinensis in golden hamster. Kyungpook Univ Med J 28: 263-273.

Choi DW, Ahn DH, Kwon OY 1990. Immune response to Clonorchis sinensis infection by peritoneal exudate cells and serum from golden hamsters sensitized by metacercariae and metabolites. Kyungpook Univ Med J 31: 8-16.

Coulson PS 1997. The radiation-attenuated vaccine against schistosomes in animal models: paradigm for a human vaccine? Adv Parasitol 39: 271-336.

Cox FE, Liew FY 1992. T-cell subsets and cytokines in parasitic infections. Immunol Today 13: 445-448.

Creaney J, Spithill TW, Thompson CM, Wilson LR, Sandeman RM, Parsons JC 1995. Attempted immunisation of sheep against Fasciola hepatica using $\gamma$-irradiated metacercariae. Int J Parasitol 25: 853-856.

Creaney J, Wilson L, Dosen M, Sandeman RM, Spithill TW, Parsons JC 1996. Fasciola hepatica: irradiation-induced alterations in carbohydrate and cathepsin-B protease expression in newly excysted juvenile liver fluke. Exp Parasitol 83: 202-215.

Dean DA 1983 Schistosoma and related genera: acquired resistance in mice. Exp Parasitol 55: 1-104.

Duan YF, Song CC, Shou GC, Zhu H, Shi JF, Fu JK, Zhang QY 1993. Effect of gamma-irradiation on infectivity of
Clonorchis sinensis metacercariae. Chin J Parasitol Dis 11: 45-49.

Hagan P, Blumenthal UJ, Dunn D, Simpson AJ, Wilkins HA 1991. Human IgE, IgG4 and resistance to reinfection with Schistosoma haematobium. Nature 349: 243-245.

Koyama K, Tamauchi H, Tomita M, Kitajima T, Ito Y 1999. Bcell activation in the mesenteric lymph nodes of resistant $\mathrm{BALB} / \mathrm{c}$ mice infected with the murine nematode parasite Trichuris muris. Parasitol Res 85: 194-199.

Lee SH, Park YH, Sohn WM, Hong ST, Chai JY 1989. The effects of gamma irradiation on the survival and development of Clonorchis sinensis metacercariae. Korean $J$ Parasitol 27:187-195.

McLaren M, Draper CC, Roberts JM, Minter-Goedbloed E, Ligthart GS, Teesdale CH, Amin MA, Omer AH, Bartlett A, Voller A 1978. Studies on the enzyme linked immunosorbent assay (ELISA) test for Schistosoma mansoni infections. Ann Trop Med Parasitol 72: 243-253.

Quan FS, Lee HJ, Chung MS, Lee JS, Rim HJ, Joo KH 2000. Chemotherapeutic efficacy of praziquantel in rats with protective immunity to Clonorchis sinensis infection. Chin J Parasitol Parasit Dis 18: 98-102.

Quan FS, Cho SW, Joo KH 2002. Proliferation and cytokine production of lymphocytes from Clonorchis sinensis-infected rats in response to stimulators in vitro. Chin J Parasitol Parasit Dis 20: 136-140.

Reiner SL, Locksley RM 1993. The worm and the protozoa: stereotyped responses or distinct antigens? Parasitol Today 9: 258-260.

Rim HJ, Yang WY, Song IC, Kim SJ 1981. On the activity of praziquantel against larvae of Clonorchis sinensis experimentally infected in rats. New Med J 24: 255-262.

Romagnani S 1997. The Th1/Th2 Paradigm in Disease, Chapman and Hall, Canada.

Song CC, Duan YF, Shou GC, Zhu H 1992. Studies on the use of cobalt-60 gamma irradiation to control infectivity of Clonorchis sinensis metacercariae. Southeast Asian J Trop Med Pub Health 23: 71-76.

Spolski RJ, Corson J, Thomas PG, Kuhn RE 2000. Parasitesecreted products regulate the host response to larval Taenia crassiceps. Parasite Immunol 22: 297-305.

Stevenson MM, Tam MF 1993. Differential induction of helper T cell subsets during blood-stage Plasmodium chabaudi AS infection in resistant and susceptible mice. Clin Exp Immunol 92: 77-83.

Stewart GL, Na H, Smart L, Seelig Jr. LL 1999. The temporal relationship among anti-parasite immune elements expressed during the early phase of infection of the rat with Trichinella spiralis. Parasitol Res 85: 672-677.

Terrazas LI, Cruz M, Rodriguez-Sosa M, Bojalil R, GarciaTamayo F, Larralde C 1999. Th1-type cytokines improve resistance to murine cysticercosis caused by Taenia crassiceps. Parasitol Res 85: 135-141.

Ungeheuer M, Elissa N, Morelli A, Georges AJ, Deloron P, Debre P, Bain O, Millet P 2000. Cellular responses to Loa loa experimental infection in mandrills (Mandrillus sphinx) vaccinated with irradiated infective larvae. Parasite Immunol 22: 173-183. 
Viana da Costa A, Huerre M, Delacre M, Auriault C, CorreiaCosta JM, Verwaerde C 2002. IL-10 leads to higher parasite persistence in a resistant mouse model of Leishmania major infection. Parasitol Int 51: 367-379.

Wales A, Kusel JR 1992. Biochemistry of irradiated parasite vaccines: suggested models for their mode of action. Parasitol Today 8: 358-363.

Zhang Y, Taylor MG, Bickle QD, Wang H, Ge J 1999 Vaccination of mice with $\gamma$-irradiated Schistosoma japonicum cercariae. Parasite Immunol 21: 111-117. 